\title{
Gastric epithelium in the duodenum: Its association with Helicobacter pylori and inflammation
}

\author{
J I Wyatt, B J Rathbone, G M Sobala, T Shallcross, R V Heatley, A T R Axon, \\ MF Dixon
}

\begin{abstract}
Duodenal biopsy specimens from 471 adults and 47 children were examined to determine the prevalence and distribution of gastric epithelium in the duodenal bulb in relation to age, gender, gastroduodenal inflammation, smoking, alcohol and consumption of nonsteroidal anti-inflammatory drugs (NSAID). Gastric metaplasia was present in the anterior wall duodenal biopsy specimen in $31 \%$, was significantly less common in patients under 17 than in adults, and was more common in males than females. In sixty two adults who underwent multiple radial duodenal biopsy gastric metaplasia was randomly distributed around the duodenal circumference; sixty three per cent of the patients with gastric metaplasia found on multiple biopsy were detected by just the anterior biopsy. Gastric metaplasia was not obviously associated with alcohol, cigarette, or NSAID consumption. While the presence of gastric metaplasia was associated with adulthood, male sex, and low fasting gastric juice pH, its extent was associated with active duodenitis and Helicobacter-associated gastritis. On logistic regression, gastric metaplasia in the duodenum and gastric Helicobacter pylori were independent predictors of active duodenitis, but were not significantly associated with inactive duodenal inflammation. $H$ pylori was observed in duodenal biopsy specimens from 32 patients, all with active duodenitis; bacteria were present only on foci of gastric metaplasia, and were more likely to be seen when the metaplasia was extensive.
\end{abstract}

It is proposed that inflammatory injury to the duodenal mucosa by $H$ pylori may stimulate the development of further gastric metaplasia, and that the area of duodenum susceptible to colonisation with $H$ pylori may therefore increase progressively until mucosal integrity is compromised and ulceration supervenes.

Helicobacter-associated chronic gastritis is very strongly associated with duodenal ulceration, being present in over $90 \%$ of patients with duodenal ulcer. ${ }^{12}$ We have previously reported that active chronic duodenitis (the pattern of inflammation commonly present at the margin of duodenal ulcers $^{3}$ ) occurs specifically in the group of patients who have both Helicobacterassociated gastritis and more than a minimal degree of metaplastic gastric epithelium in the duodenum. ${ }^{4}$ Gastric metaplasia is common in the proximal duodenum, where it is believed to be induced by acid injury. ${ }^{3}$ Helicobacter pylori colonises only gastric type epithelium $^{1245}$ and is therefore able to infect the duodenum only when gastric metaplasia is present. We have proposed that the combination of $H$ pylori and gastric metaplasia induced by acid are the prerequisites for the development of active duodenitis, and that this inflammation impairs mucosal defences, leading ultimately to duodenal ulceration. ${ }^{6}$

Duodenal ulcer is a multifactorial condition. ${ }^{7}$ The aetiology is closely related to enhanced acid secretion, but has been found to be influenced by many other factors including gender, genetic predisposition, alcohol consumption, drug intake, smoking, and most recently $H$ pylori infection. Some of these factors may also affect the occurrence of metaplastic gastric epithelium in the duodenum and consequently influence susceptibility to duodenitis and ulceration.

The aim of this study was to investigate the prevalence and distribution of gastric epithelium in the duodenum in relation to age, gender, alcohol consumption, smoking, fasting gastric juice $\mathrm{pH}$, ingestion of nonsteroidal anti-inflammatory drugs (NSAID) and gastroduodenal inflammation.

\section{Methods}

Four hundred and seventy one patients with dyspepsia who had upper gastrointestinal endoscopy with biopsy performed at defined sites as part of three dyspepsia studies were investigated. The studies had been approved by the hospital ethical committees and the patients had given informed consent. (These patients include 252 of the patients in a previous study. ${ }^{4}$ ) All of the patients (aged 1884,209 of them male) had a biopsy specimen taken from the anterior wall of the first part of the duodenal mucosa as well as specimens from constant sites in the antral and body gastric mucosa.

To determine the distribution of gastric epithelium in the duodenum and to estimate 


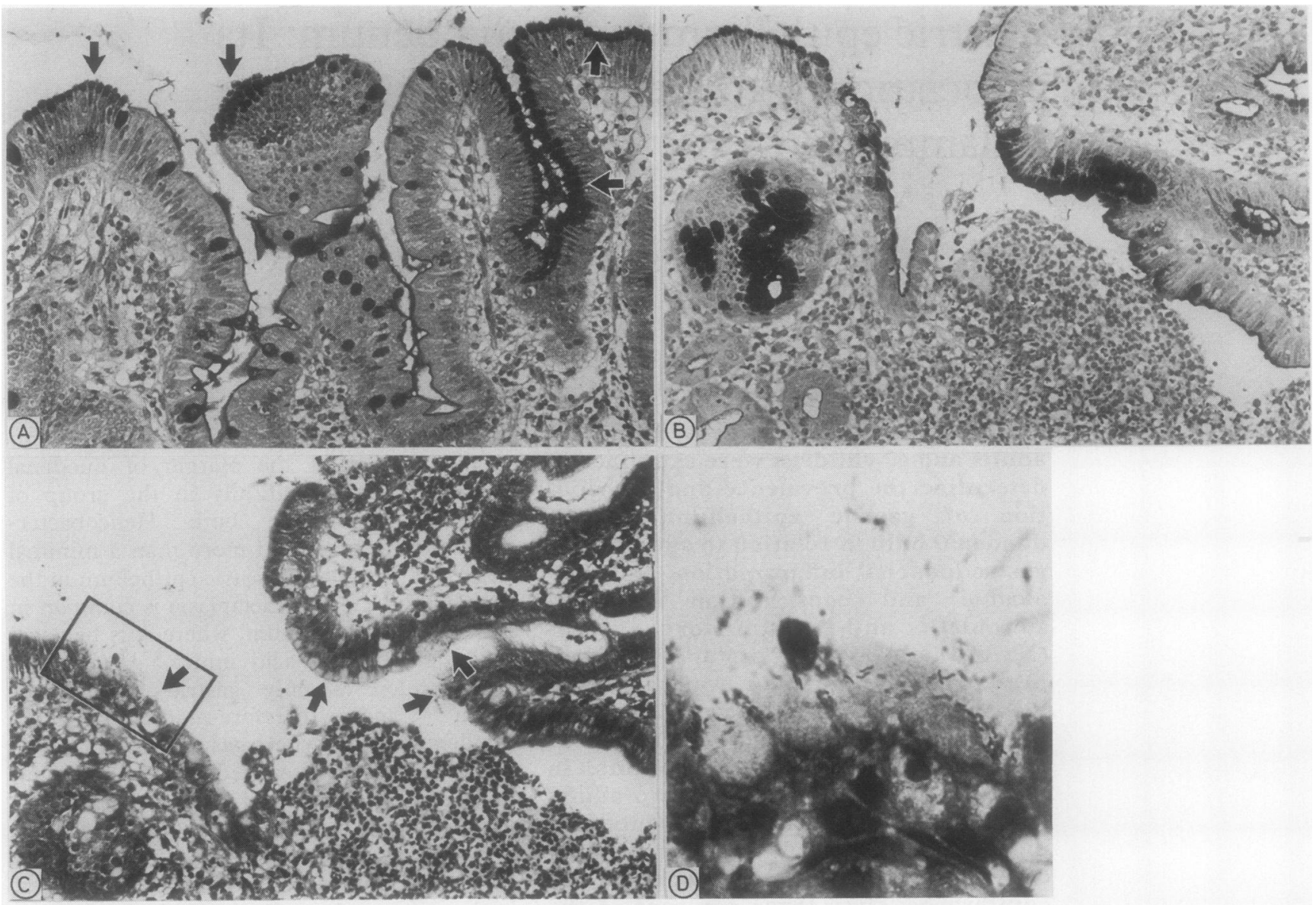

Figure 1 A Gastric metaplasia present in a duodenal biopsy specimen which is otherwise normal. The metaplastic epithelium (arrows) is most of ten present on the tips of villi (alcian blue/PAS).

Figure 1B Duodenal biopsy specimen showing active duodenitis with surface erosion occurring in an area of gastric metaplasia (alcian blue/PAS).

Figure 1C The same field as seen in Fig 1B; $H$ pylori can be seen colonising the metaplastic gastric epithelium on either side of the eroded area (arrows) (modified Giemsa stain).

Figure $1 D$ High magnification to show $H$ pylori closely applied to the surface of the gastric type cells (modified Giemsa stain).

the sampling error of a single biopsy specimen additional directed duodenal biopsy specimens from the posterior wall, roof, and floor of the first part of the duodenum were collected prospectively from 62 of the patients (aged 18-74, 28 of the male), and 38 patients in this group also had anterior and posterior biopsy specimens taken from the second part of the duodenum.

Details of endoscopic findings, ulcer history, smoking habit, and alcohol and NSAID consumption were recorded on pro-forma record sheets for all of the adult patients. The $\mathrm{pH}$ of fasting gastric juice aspirated at the beginning of endoscopy was measured in 94 .

Forty seven children aged under 17 from whom one to five (median two) gastric and one to two (median one) duodenal biopsy specimens were available were included in the study. This material was examined retrospectively and represented all of the paediatric gastroduodenal biopsy specimens obtained at St James's Hospital between 1981 and 1988.

HISTOLOGICAL ANALYSIS

All biopsy specimens were stained with haematoxylin and eosin and examined by one pathologist for gastritis and duodenitis, using standard criteria as described previously. ${ }^{48}$
"Chronic duodenitis" was characterised by a definite increase in lamina propria inflammatory cells together with flattening of villi and evidence of epithelial cell damage. If neutrophils had infiltrated the lamina propria and epithelium in addition to evidence of changes indicative of chronic duodenitis the appearances were classified as "active duodenitis". The presence of gastric epithelium was not a diagnostic criterion for active duodenitis. Mild changes in villous architecture and minor increases in lamina propria cellularity were designated "no significant duodenitis".

Sections of all biopsy specimens were also stained by the modified Giemsa technique for $H$ pylori, ${ }^{9}$ and duodenal biopsy specimens were stained by alcian blue/periodic acid Schiff for the detection of gastric epithelium where this was not apparent on haematoxylin and eosin staining. Gastric epithelium was defined by the presence of adjacent surface epithelial cells containing periodic acid Schiff positive neutral mucin (fig 1). The extent of the gastric epithelium was graded 1-4 depending on whether one pathologist estimated that it covered less than $5 \%, 5-20 \%, 20-50 \%$ or greater than $50 \%$ of the surface in the biopsy specimen respectively, and this grad- 
Table 1 Prevalence and extent of gastric metaplasia (GM) in 62 patients with multiple duodenal biopsy specimens

\begin{tabular}{|c|c|c|c|c|c|c|c|}
\hline \multirow{2}{*}{$\begin{array}{l}\text { Number of } \\
\text { biopsy specimens } \\
\text { with gastric } \\
\text { metaplasia }\end{array}$} & \multirow{2}{*}{$\begin{array}{l}\text { Number (\%) } \\
\text { of patients }\end{array}$} & \multicolumn{4}{|c|}{$\begin{array}{l}\text { Maximum gastric } \\
\text { metaplasia grade } \\
\text { for each patient }\end{array}$} & \multirow{2}{*}{$\begin{array}{l}\text { Median gastric } \\
\text { metaplasia grade } \\
\text { of biopsy specimen } \\
\text { with gastric } \\
\text { metaplasia }\end{array}$} & \multirow{2}{*}{$\begin{array}{l}\text { Mean gastric } \\
\text { metaplasia grade } \\
\text { of biopsy specimen } \\
\text { with gastric } \\
\text { metaplasia }\end{array}$} \\
\hline & & 1 & 2 & 3 & 4 & & \\
\hline 0 & $27(0)^{\star}$ & - & - & - & - & - & - \\
\hline 1 & $11(36)$ & 8 & 2 & - & 1 & 1 & 1.4 \\
\hline 2 & $5(20)$ & 4 & - & - & 1 & 1 & $1 \cdot 3$ \\
\hline 3 & $12(100)$ & 1 & 2 & 3 & 2 & 2 & $2 \cdot 0$ \\
\hline 4 & $12(100)$ & 1 & 2 & 3 & 6 & 3 & $2 \cdot 4$ \\
\hline
\end{tabular}

*Percent of these patients with gastric metaplasia in the anterior duodenal biopsy specimen.

ing was used to relate gastric metaplasia to the other variables in the results section. The degree of gastric metaplasia in 100 consecutive duodenal biopsy specimens was also graded independently by a second histopathologist to determine the degree of interobserver variation.

Statistical analysis was performed using the $\chi^{2}$ test, Fisher's exact test, the Wilcoxon and Kruskall Wallis methods for ranked, nonparametric variables and $\kappa$ statistics for the interobserver variation. Multiple regression and logistic regression analyses were performed using the SAS package. ${ }^{10}$

\section{Results}

A total of 780 duodenal biopsy specimens from 518 patients were studied. Biopsy specimens from 174 patients $(33.6 \%, 95 \%$ confidence limit $29 \cdot 5-37 \cdot 7 \%$ ) contained gastric epithelium, the extent of which varied from small foci of at least three adjacent epithelial cells, to areas comprising the whole of the biopsy specimen surface. Gastric epithelium was often but not always associated with a degree of villous blunting.

In five patients gastric epithelium was seen to overlie fully differentiated fundic-type gastric mucosal glands without any inflammation; this was considered to represent congenital gastric heterotopia in the duodenum, as described previously. ${ }^{411}$ In all other cases the gastric epithelium occurred without this type of mucosa beneath, fulfilling the criteria for "gastric metaplasia". ${ }^{38}$ This change tended to be present more frequently on villous tips than on the sides or in mucosal crypts. The periodic acid Schiff positive epithelium varied from cells with abundant cytoplasmic mucin to cells where the periodic acid Schiff positive brush border of normal enterocytes was replaced by a narrow zone of cytoplasmic positivity, often with underlying periodic acid Schiff positive granules within the cytoplasm. Both were included in the definition of gastric metaplasia in this study, although it was apparent that in active inflammation the mucin content of the cells tended to be reduced.

Table 2 Association between gastric metaplasia and age

\begin{tabular}{|c|c|c|c|c|c|c|c|}
\hline \multirow[b]{2}{*}{ Age } & \multicolumn{5}{|c|}{ Grade of gastric metaplasia } & \multirow{2}{*}{$\begin{array}{l}\text { Total number } \\
\text { of patients }\end{array}$} & \multirow{2}{*}{$\begin{array}{l}\text { Total number } \\
\text { with gastric } \\
\text { metaplasia }(\%)\end{array}$} \\
\hline & None & 1 & 2 & 3 & 4 & & \\
\hline $\begin{array}{l}<20 \\
20-39 \\
40-59 \\
>60\end{array}$ & $\begin{array}{r}54 \\
97 \\
119 \\
87\end{array}$ & $\begin{array}{r}3 \\
20 \\
33 \\
18\end{array}$ & $\begin{array}{r}1 \\
15 \\
25 \\
14\end{array}$ & $\begin{array}{l}-9 \\
3 \\
4\end{array}$ & $\begin{array}{l}-4 \\
8 \\
4\end{array}$ & $\begin{array}{r}58 \\
145 \\
188 \\
127\end{array}$ & $\begin{array}{c}4(7) \\
48(33) \\
69(37) \\
40(31)\end{array}$ \\
\hline Total & 357 & 74 & 55 & 16 & 16 & 518 & $161(31)$ \\
\hline
\end{tabular}

DISTRIBUTION OF GASTRIC METAPLASIA IN THE DUODENUM

Of the 62 patients from whom multiple duodenal biopsy specimens were taken, 35 (56\%) (95\% confidence limit 43-69\%) had gastric metaplasia in at least one. In $22(35.5 \%)$ (95\% confidence limit $45-79 \%$ ) gastric metaplasia was present in the anterior biopsy specimen, a prevalence similar to the $33 \%$ in the group of 409 adult patients from whom single anterior biopsy specimens had been taken. Therefore, in this group the single anterior duodenal biopsy detected 22 out of 35 $(63 \%)$ patients with gastric metaplasia found by multiple biopsy. Gastric metaplasia was distributed randomly around the circumference of the duodenum; the numbers of patients with gastric metaplasia in the anterior, posterior, roof and floor biopsy specimens were $22,17,27$, and 20, respectively. Gastric metaplasia was present in the biopsy specimens of the second part of the duodenum in only two of the 38 patients studied; both of these had gastric metaplasia in all four of the first part biopsy specimens.

The extent of gastric metaplasia in the biopsy specimens from the first part of the duodenum is shown in table 1. In general, gastric epithelium was either found as small foci in one to two specimens, or was present in three to four, in which case it tended to be more extensive. Both the median and the mean grade of gastric metaplasia for each biopsy specimen increased significantly with increasing prevalence or gastric metaplasia among the radial biopsy specimens $(p=0.0051)$.

\section{RELATION OF GASTRIC METAPLASIA TO AGE AND} GENDER

The prevalence of gastric epithelium in anterior duodenal biopsy specimens in patients according to age is shown in table 2 . It was present significantly less frequently in children $(p<0.0001)$ but did not vary with age among the adult patients. Gastric metaplasia was present in $41 \%$ of male patients and in $23 \%$ of female patients $(p=0.0005)$.

\section{RELATION OF GASTRIC METAPLASIA TO}

GASTRODUODENAL INFLAMMATION

Gastric metaplasia was not seen in duodenal biopsy specimens from any of the 17 patients who had chronic atrophic gastritis and intestinal metaplasia affecting body-type gastric mucosa, but was present in 12 out of $57(21 \%)$ patients with intestinal metaplasia in the antrum. Otherwise the prevalence of duodenal gastric metaplasia did not vary with gastric inflammation. Gastric metaplasia was present in the anterior biopsy specimen in $34 \%$ of $H$ pylori positive patients and $32 \%$ of patients without $H$ pylori. The extent of the metaplasia, however, was signficantly greater in those patients with Helicobacter-associated gastritis than in the others, with $20.8 \%$ of the $H$ pylori positive patients having more than $5 \%$ gastric metaplasia compared with $14.9 \%$ of the $H$ pylori negative patients ( $p=0.002$ ) (table 3 ).

There was a clear, quantitative relation between gastric metaplasia and active duodenal 
Table 3 Extent of gastric metaplasia in anterior duodenal biopsy specimen in relation to $H$ pylori state

\begin{tabular}{|c|c|c|c|c|c|c|c|}
\hline \multirow{2}{*}{$\begin{array}{l}\text { H pylori } \\
\text { state }\end{array}$} & \multicolumn{5}{|c|}{ Grade of gastric metaplasia } & \multirow[b]{2}{*}{ Total } & \multirow{2}{*}{$\begin{array}{l}\text { Total (\%) } \\
\text { with gastric } \\
\text { metaplasia }\end{array}$} \\
\hline & None & 1 & 2 & 3 & 4 & & \\
\hline $\begin{array}{l}\text { Positive } \\
\text { Negative }\end{array}$ & $\begin{array}{l}176 \\
139\end{array}$ & $\begin{array}{l}36 \\
35\end{array}$ & $\begin{array}{l}28 \\
25\end{array}$ & $\begin{array}{r}11 \\
5\end{array}$ & $\begin{array}{r}16 \\
0\end{array}$ & $\begin{array}{l}267 \\
204\end{array}$ & $\begin{array}{l}91(34) \\
65(32)\end{array}$ \\
\hline
\end{tabular}

inflammation. Active duodenitis was rarely seen in the absence of gastric metaplasia and showed an increasing prevalence in biopsy specimens with increasing extent of gastric metaplasia (fig 2). This applied only to active duodenitis; in patients with chronic duodenitis and those without clinically important duodenitis the duodenal histology showed no significant association with gastric metaplasia.

Active duodenitis was present in $\mathbf{5 6}$ anterior biopsy specimens and $H$ pylori was observed in 32 of these. $H$ pylor $i$ were patchily distributed and seen only on areas of gastric metaplasia; the bacteria were more likely to be seen in biopsy specimens with larger areas of gastric epithelium (fig 2). Overall, 43 out of the 512 patients had a duodenal ulcer, and $40(93 \%)$ of these had Helicobacter-associated gastritis; the other three had all recently taken NSAID. In $29(67 \%)$ of the patients with duodenal ulcer gastric metaplasia was identified in the anterior biopsy specimen, compared with $30.7 \%$ of adults without duodenal ulcer $(p<0.0001)$. Twenty nine of the patients with duodenal ulcer had duodenitis, which was active in 19, and $H$ pylori was seen in the duodenal biopsy specimen in 12. Thirty seven patients had active duodenitis not associated with duodenal ulceration, and $H$ pylori was observed in 20 of these biopsy specimens ( $p>0.05)$.

\section{REPRODUCIBILITY OF GRADING OF GASTRIC METAPLASIA}

The two pathologists agreed over the presence or absence of gastric metaplasia in 94 out of 100 biopsy specimens ( $\kappa$ value $=0.88$ ); in the six cases of disagreement five were graded as 1 ( $<5 \%$ metaplasia) by one of the pathologists.

Figure 2 Histogram showing the relation between duodenal inflammation and grade of gastric metaplasia.

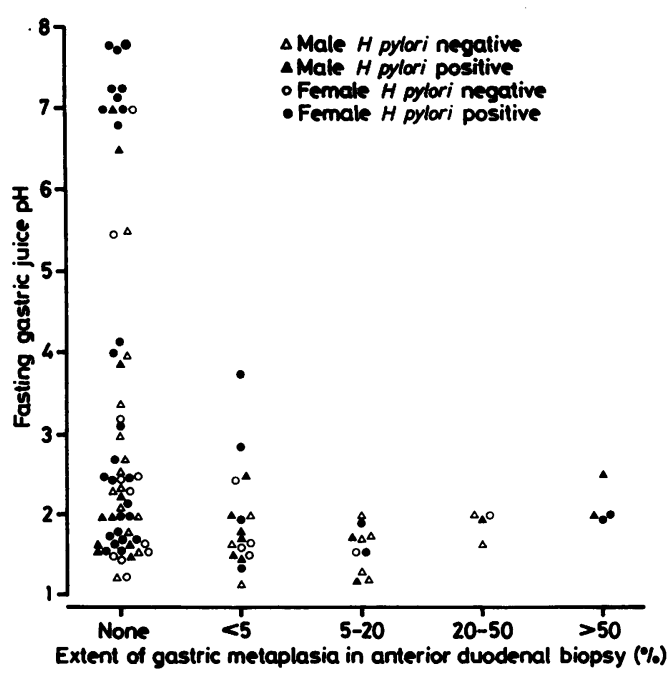

Figure 3 The relation between gastric metaplasia in the duodenum and fasting gastric juice $p H$, gender, and $H$ pylori state in 94 patients.

When the agreement over the grading of the extent of metaplasia (graded 0-4) was tested, there was concurrence in 79 out of 100 of the biopsy specimens, and in only five cases was there more than one grade difference in the allocations. This gave a $\kappa$ value of 0.66 , which indicates a very high level of agreement over the five categories. The biopsy specimens in which there was more than one grade of disagreement tended to be those where the gastric metaplasia was characterised by only a narrow zone of periodic acid Schiff positivity beneath the epithelial cell surface (so-called "immature" gastric metaplasia). ${ }^{12}$

\section{RELATION OF GASTRIC METAPLASIA TO OTHER FACTORS}

There was a significant association between gastric metaplasia and a low fasting gastric juice $\mathrm{pH}(\mathrm{p}=0.0001)$ (fig 3). Gastric metaplasia occurred in patients with low fasting $\mathrm{pH}$ regardless of their gender or $H$ pylori state. No significant association was found between the presence or extent of gastric metaplasia and a history of smoking, alcohol consumption, or NSAID.

Multiple regression analysis showed that for the 94 patients with fasting gastric juice $\mathrm{pH}$ measurements, male gender was not an independent predictor of gastric metaplasia after $\mathrm{pH}$ had been taken into account. Logistic regression showed that Helicobacterassociated gastritis and the degree of gastric metaplasia were independent predictors of active duodenitis ( $\mathrm{p}=\mathbf{0 . 0 0 0 1}$ for gastric metaplasia, $\mathrm{p}=0.0321$ for $H$ pylori state), but neither showed any significant association with duodenal inflammation which was not active. If gastric juice $\mathrm{pH}$ was substituted in the model for the extent of gastric metaplasia, then $H$ pylori state and gastric juice $\mathrm{pH}$ remained significant independent predictors of active duodenitis ( $\mathrm{p}=0.01$ for $\mathrm{pH}, \mathrm{p}=0.027$ for $\dot{H}$ pylori state).

\section{Discussion}

It is now widely accepted that $H$ pylori infec- 
tion of the gastric mucosa produces an active chronic inflammatory response. ${ }^{2}$ Various pathogenic mechanisms have been proposed for $H$ pylori $i^{13}$; all require a close proximity of the organism to the epithelium for epithelial damage to occur. $H$ pylori only colonises gastric type epithelium; therefore, the presence of gastric epithelium in the duodenum is essential for duodenal infection by the organism. We have proposed that active duodenitis develops when $H$ pylori colonises foci of gastric metaplasia in the duodenum, and that because gastric metaplasia is considered to be a response to acid injury, this sequence of events can account for the independent role of acid and $H$ pylor in duodenal inflammation.

The previously suggested quantitative association between active duodenitis and gastric metaplasia ${ }^{1114}$ has been confirmed in this study in which the more extensive the gastric metaplasia, the more likely there was to be active duodenitis. This observation can be explained by the development of more extensive gastric metaplasia in patients with duodenitis in response to the injury caused by the inflammation itself. If gastric metaplasia provides the "foothold" in the duodenum for $H$ pylori colonisation, then a vicious circle may develop by which $H$ pylori infects foci of gastric metaplasia and the resulting duodenitis leads to increasing areas of gastric metaplasia susceptible to further $H$ pylori infection. Duodenal ulcer may supervene when the duodenitis becomes severe, and the inflamed mucosa can no longer maintain its integrity against "acid attack", perhaps as a result of "high output failure" of epithelial regeneration. ${ }^{15}$

We have found that there is a lower prevalence of gastric epithelium in the duodenum in children than in adults. This is important for proving that this is acquired rather than congenital in origin, as had been suggested by Marshall. ${ }^{16}$ Parietal cells are usually present in small numbers in the antral mucosa ${ }^{17}$ and their presence in the duodenum of patients with ulcers, as recently highlighted by Carrick, ${ }^{18}$ might therefore be expected in foci of gastric metaplasia. We restrict the term "heterotopia" to fully organised gastric fundic tissue, which is a rare cause of duodenal nodularity and is presumed to be congenital, and in our experience and that of Shousha ${ }^{11}$ not associated with duodenal ulcer disease.

Like Patrick et al we rarely found gastric metaplasia beyond the first part of the duodenum $^{19}$ and only in patients with extensive gastric metaplasia in the first part. There is a wide variation in the extent of gastric metaplasia within the first part of the duodenum and it seems to be randomly distributed around the circumference, at least in patients without duodenal ulcer. Investigators studying both duodenitis ${ }^{20}$ and gastric metaplasia ${ }^{21}$ in patients with duodenal ulcer have found the abnormality to be more common at the margin of the ulcers or at the site of a healed ulcer than elsewhere. The findings from our study suggest that in the absence of duodenal ulcer the distribution of gastric metaplasia depends on proximity to the pylorus and that it does not occur preferentially in sites characteristic of duodenal ulcer. Therefore, factors determining site of a chronic duodenal ulcer-for example, possible localised mucosal ischaemia-differ from those which affect the distribution of gastric metaplasia.

The conventional view of gastric metaplasia in the proximal duodenum is that it is an acquired change in response to acid injury. ${ }^{3}$ Our results with respect to fasting gastric juice $\mathrm{pH}$ support this, although total acid secretory capacity was not measured. The greater prevalence of gastric metaplasia in men may result from their greater acid secretory capacity, which would be consistent with the correlation between male gender and $\mathrm{pH}$ in our multivariate analysis. There is additional support for an acid induced mechanism, from observations of extensive gastric metaplasia in patients with Zollinger-Ellison syndrome, ${ }^{22}{ }^{23}$ the correlation of gastric epithelium with maximal acid output, ${ }^{19}$ and from animal studies. ${ }^{24-26}$ These have been reviewed previously. ${ }^{27}$ Recent studies in rats by Tatsuta et $a l^{28}$ have clearly shown that the gastric metaplasia, which developed in response to chemically induced duodenal injury in rats, was significantly more extensive and prolonged in the animals rendered hyperchlorhydric with tetragastrin, and did not occur in a group of rats which had undergone vagotomy.

Metaplasia is a non-specific response to mucosal injury, and factors other than acid peptic damage to the mucosa may result in gastric metaplasia in the duodenum. Two previous studies have shown an association between heavy alcohol consumption and gastric metaplasia. ${ }^{29}{ }^{30}$ This was not the case in our study, but our series included few heavy drinkers. Similarly, like Carrick et al ${ }^{18}$ we have not found support for the view that mucosal injury as a result of cigarette smoking or NSAID consumption leads to increased gastric metaplasia in the duodenum.

In this paper we have directed our attention to gastric metaplasia in relation to its role in duodenal ulcer pathogenesis. Its detection is also of relevance in routine histopathology, because it is a characteristic of the pattern of duodenal inflammation associated with peptic ulcer disease. It also identifies those areas of the biopsy specimen surface where $H$ pylori can be sought. Gastric metaplasia develops in a patchy distribution, and its detection therefore depends on sampling error. In 62 of our patients this problem was addressed by taking multiple biopsy specimens; we found that the prevalence of gastric metaplasia decreased with distance from the pylorus, but was not dependent on the biopsy site radially in the first part of the duodenum, although it tended to be more common in the anterior and roof biopsy specimens. One biopsy specimen from the anterior wall (the position most readily biopsied) would detect 22 out of $35(63 \%)$ patients with gastric metaplasia on multiple biopsy; two biopsy specimens (anterior and roof) detected 33 out of $35(94 \%)$ patients with gastric metaplasia. We agree with Frierson et $a l^{31}$ that the alcian blue/periodic acid Schiff stain was useful 
in highlighting the areas of gastric metaplasia, and we found good agreement between different histopathologists in detecting this feature.

In summary, this study has examined the association between gastric metaplasia in the duodenum and other factors related to duodenal ulcer disease. We found that foci of gastric metaplasia in the duodenal epithelium were an acquired change and were more common in men, perhaps because of their greater acid output. Gastric metaplasia was not related to alcohol, smoking, or NSAID consumption. Gastric metaplasia was not more common in $H$ pylori positive patients, but if present was greater in extent; this suggested that the mucosal injury related to active duodenitis in these patients may act as a further stimulus to metaplasia. Thus a positive feedback loop may be set up whereby the area of duodenal mucosa susceptible to $H$ pylori colonisation progressively increases, resulting in increasing inflammation until mucosal integrity is compromised and ulceration occurs.

1 Blaser MJ. Gastric Campylobacter-like organisms, gastritis, and peptic ulcer disease. Gastroenterol 1987;93:371-83.

2 Graham DY. Campylobacter pylori and peptic ulcer disease. Gastroenterol 1989;96:615-25.

3 Joffe SN, Lee FD, Blumgart LH. Duodenitis. Clin Gastroenterol 1978;7:635-50.

4 Wyatt JI, Rathbone BJ, Dixon MF, et al. Campylobacter pyloridis and acid-induced gastric metaplasia in the pathogenesis of duodenitis. J Clin Pathol 1987;40:841-8.

5 Thomas JM, Poynter D, Gooding C, et al. Gastric spiral bacteria. Lancet 1984;ii:100.

6 Wyatt JI, Rathbone BJ, Dixon MF, et al. Campylobacter pylori and development of duodenal ulcer. Lancet 1988; 118-9.

7 Misiewicz JJ, Pounder RE. Peptic ulcer. In: Weatherall DJ, Ledingham JGG, Warrell DA, eds. Oxford textbook of medicine. 2nd ed. Oxford: Oxford University Press, 1987: medicine.

8 Whitehead R. Mucosal biopsy of the gastrointestinal tract. 3rd ed. Philadelphia: WB Saunders, 1984.

9 Grey SF, Wyatt JI, Rathbone BJ. Simplified techniques for identifying gastric Campylobacter pyloridis on tissue sections. J Clin Pathol 1986;39:1279-80

$10 S A S / S T A T$ User's Guide. Release 6.03 Edition. SAS Institute Inc, Cary, NC, USA, 1988.
11 Shousha S, Spiller RC, Parkins RA. The endoscopically abnormal duodenum in patients with dyspepsia: biopsy abnormal duodenum in patients with dyspepsia:

12 Gregory MA, Spitaels JM. Variations in the morphology of villous epithelial cells within $8 \mathrm{~mm}$ of untreated duodena ulcers. J Pathol 1987;53:109-19.

13 Rathbone BJ, Wyatt JI, Heatley RV. Possible pathogenetic pathways of Campylobacter pylori in gastro-duodena disease. Scand J Gastroenterol 1987;23(suppl 142):40-3.

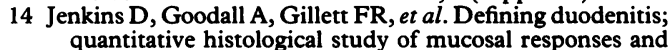
their correlations. J Clin Pathol 1985;38:1119-26.

15 Bransom CJ, Boxer ME, Palmer KR, et al. Mucosal cell proliferation

16 Marshall BJ, McGechie DB, Rogers PA, Glancy RJ Pyloric campylobacter infection and gastroduodenal disease. Med campylobacter infection

17 Hara M, Harasawa S, Tani N, Miwa T, Tsutsumi Y. Gastric metaplasia in duodenal ulcer; histochemical considerations of its pathophysiological significance. Acta Patho Japan 1988;38:1011-8.

18 Carrick J, Lee A, Hazell S, Ralston M, Daskalopoulos G. Campylobacter pylori, duodenal ulcer, and gastric metaplasia: possible role of functional heterotopic tissue in ulcerogenesis. Gut 1989;30:790-7.

19 Patrick WJA, Denham D, Forrest APM. Mucous change in the human duodenum; a light and electron microscopic study and correlation. Gut 1974;15:767-76.

20 Paoluzi P, Pallone F, Palazzesi $P$, et al. Frequency and exten of bulbar duodenitis in duodenal ulcer. Endoscopic and histological study. Endoscopy 1982;14:193-5.

21 Marshall BJ, Warren JR, Blincow ED, et al. Prospective double blind trial after eradication of Campylobacter pylori. Lancet 1988;ii: $1437-41$.

22 James AH. Gastric epithelium in the duodenum of a patien with gastric hyperacidity. 2nd World Congress of Gastroenterology, Munich, 1962;II:540-3;(1963).

23 Parrish JA, Rawlins DC. Intestinal mucosa in Zollinger Ellison syndrome. Gut 1965;6:286-9.

24 Gaskin RJ, Gad A, Barros AAJ, et al. Natural history and morphology of secretagogue-induced ulcers in rats. Gastroenterol 1975;69:903-10.

25 Rhodes J. Experimental production of gastric epithelium in the duodenum. Gut 1964;5:454-8.

26 Florey HW, Jennings MA, Jennings DA, et al. The reactions of the intestine of the pig to gastric juice. J Pathol Bacteriol of the intestine of

27 Wyatt JI. Relationship of Campylobacter pylori to duodenal ulcer disease. In: Blaser MJ, ed. Campylobacter pylori in gastritis and peptic ulcer disease. New York: Igaku-Shoin, 1989.

28 Tatsuta $M$, Ishii $H$, Yamamura $H$, Yamamoto R, Taniguch $H$. Enhancement by tetragastrin of experimental induction of gastric epithelium in the duodenum. Gut 1989;30: 311-5.

29 Lev R, Thomas E, Paul FF. Pathological and histomorphometric study of the effects of alcohol on the human duodenum. Digestion 1980:20:207-13.

30 Shousha S, Barrison IG, El-Sayeed W, et al. A study of incidence and relationship of intestinal metaplasia on incidence and relationship of intestinal metaplasia on gastric antrum and gastric metaplasia of duodenum in $311-6$

31 Frierson HF, Caldwell SH, Marshall BJ. Duodenal bulb biopsy findings for patients with non-ulcer dyspepsia with or without Campylobacter pylori gastritis. Modern Pathol 1990;3:271-7. 